\title{
Science Learner's Material for Grade 10: Examining Multicultural and Gender Representation
}

\author{
Norjanah Umpara Derico ${ }^{1}$, Wardah Dirampatun Guimba ${ }^{2}$, Jerryk Comawas Alico ${ }^{3}$ \\ ${ }^{1}$ Sultan Langco National High School, DepEd-ARMM, Division of Lanao del Sur II, Malabang, Philippines \\ ${ }^{2}$ College of Education, Mindanao State University, Marawi City, Philippines \\ ${ }^{3}$ Senior High School, Mindanao State University, Marawi City, Philippines
}

Email address:

norjanahderico86@gmail.com (N. U. Derico), mataidtweety@gmail.com (W. D. Guimba), alico_jerryk@yahoo.com (J. C. Alico)

\section{To cite this article:}

Norjanah Umpara Derico, Wardah Dirampatun Guimba, Jerryk Comawas Alico. Science Learner's Material for Grade 10: Examining Multicultural and Gender Representation. Advances in Sciences and Humanities. Vol. 5, No. 1, 2019, pp. 20-26.

doi: 10.11648/j.ash.20190501.13

Received: December 17, 2018; Accepted: January 16, 2019; Published: February 9, 2019

\begin{abstract}
Science textbooks are presumed to be indigenized, culturally sensitive, integrated with personal and ethical aspect of life and socially and environmentally aligned to the basic tenets of the k-12 basic education curriculum. This study is conducted to add to scanty literature on textbook analysis using Bennett's four core values of comprehensive multicultural curriculum in the Philippine context. These four core values are: (i) respect for human rights and human dignity, (ii) acceptance and appreciation and diversity, (iii) responsibility to the world community, and (iv) respect to the earth. Content analysis was employed in this study where both "manifest content" i.e. the visible, surface content and "latent content" or the underlying meaning of manifest content was examined. The researchers read and analyzed the content of the textbook based on the definition or set of words given then transcribed it on the checklist developed based on Bennett Conceptual model of comprehensive multiculturalism. After analyzing the data, the distribution and frequency of the core values were tallied, and calculated for its percentage and chi square test. Findings revealed that the Science Learner's Material for Grade 10 elusively reflected multiculturalism in the textbook. However, portrayals of gender inequalities appeared in the textbook, males outnumbered the females. Teachers play major roles infusing and emphasizing multicultural elements in the teaching and learning process in the classroom. Textbooks developers need to pay more attention in incorporating multicultural elements in the Science textbooks and should promote gender equality representation in the textbook.
\end{abstract}

Keywords: Content Analysis, Science Textbook, Multicultural Reflection, Gender

\section{Introduction}

The Philippines is known for being one of the most culturally diverse nations in the world. It is a nation of different races, cultures, traditions, and religion. It ranks as the 8th among 240 countries in terms of ethnic diversity. Of its 7,641 islands, people within speak different dialects. There are those who speak Tagalog, Ilocano, Ibanag, Ilonggo, Chavacano, Meranao and a lot more, in fact Philippines have more than 170 local languages and dialects but all are called Filipinos. Indeed, there is diversity in the Philippines.

The Philippine Constitution Article II, s. 22 stated that the country "recognizes and promotes the rights of indigenous cultural communities within the framework of national unity and development." Nevertheless, the Philippine government is still facing difficulty in managing the country's cultural diversity. There are many conflicts arising in every part of the country such as the rebellion of the NPA's in Luzon, the Abu Sayyaf in Sulu, and Maute group in Lanao del Sur. The Marawi Siege last May 23, 2017 is just one sign. These series of conflicts in different parts of the Philippines may be attributed to lack of socio-cultural consciousness and differences in principles that each group possessed and fought for.

The society we live in is a society of mix-culture [26 as cited by 20]. Conflicts arise due to lack of understanding of other's culture, ethnicity, social class, and beliefs. The imbalance of power between the dominant and the dominated cultures has created years of armed conflicts, aggression, and resistance. The case of Christian-Muslim conflict in the 
Philippines is a typical example of imbalance in the appreciation of diverse cultures. It is the lack of understanding of other cultures that weakens the society. The practice of multicultural education is one of the many answers for peace. Approaches to multicultural education need to be given emphasis in searching for answers for cultural diversities.

The conflicts between different cultures is happening not only in the Philippines but around the world and the main reasons are the differences and dissimilarities in ethnicities, culture groups, religions, social-economic status, and individual beliefs. Scholars and researchers tried to find solutions to end these issues. A lot of researches related to multicultural diversity and studies on multicultural infusion in educational curriculum arise. The crucial role of education in the promotion of multicultural curriculum was also recognized around the world.

Education plays an important role in dealing with a community that faces diverse ethnicities where prejudices and stereotypes are prevalent and inevitable. The education system is one of the best means to mold the minds of new generation towards peace and harmony despite the differences in culture, religion, linguistic, ethnicities and ideologies in life.

As insisted by scholars, it became imperative that multicultural education be infused to school curriculum/textbook if schools are to achieve goals of developing citizens who are knowledgeable, skillful and have desired values necessary to function in a multicultural democratic society $[2,3,10]$.

Multicultural education is defined as "whose major aim is to create equal educational opportunities for students from diverse racial, ethnic, social-class, and cultural groups" [4]. Multicultural Education is the current educational instruction that can eradicate discrimination and oppression. One of its goals is to provide students optimum education through friendly and secure ambient. Multicultural pedagogy is essential in managing pluralistic society or diversity in classroom. Multicultural Education is quite literally the pedagogy of oppressed individuals who are longing or hankering for equality and respect such as indigenous people, religious minorities, women, homosexual, differently-abled, and others.

In relation to the statements above about the importance of multicultural education in the curriculum, textbooks play significant roles. Textbooks are made based on curriculum concepts or designed that teacher and students can follow inside the classroom. It served as tangible materials that convey the curriculum in the classroom. Furthermore, textbooks are powerful tools in shaping the hearts and minds of students. Hence, it is very crucial to analyze textbooks [12].

\section{Previous Researches}

Terra and Bromley [25] analyzed 548 secondary social Science textbook used around the world. It was a crossnational analyze started from 1950-2010. Their study showed textbooks increasingly discuss women, children, immigrants and refugees, indigenous peoples, gays and lesbians, and other minorities as experiencing discrimination, marginalization or exclusion in society. In addition to depicting social inequities, textbooks also increasingly described groups as individuals with bearing rights.

In the study of Gaul [12] which aims to analyze the representation of Sri Lankan's communities in history textbooks revealed that history textbooks do not support the state aspiration or goals in reconstructing their country from a decade of war. Instead of upholding positive acknowledgment of difference and diversity, they continually ignore minority groups and focused or highlighted Sinhales values and traditions as the national culture. History textbooks do acknowledge differences between the communities with limitation.

Stoilescu [22] conducted a critical multicultural analysis of a Romanian Language textbook used in grade one and two elementary level. The textbook that was analyzed was the first book that offers the primary attempt to recognize and promote the Romanian-Canadian identity. Results show that the content of the textbook has civic education, literature, and folk traditions. However, it seems that the subjects and texts are generally part of the Canadian multicultural education curriculum and still there are presence of different biases from the Romanian side. The textbook further offers a strong resistance for Romanian immigrants. Thus, reformatting the textbook in a multicultural, multilingual and multimodal framework is recommended by the researcher.

Jackson [17] analyzed Liberal studies textbooks in order to determine how diversity and ethnic, cultural, and religious differences are represented in the texts. Based on the analysis, multicultural education appears inadequate and the textbooks did not provide enough or accurate information on how diversity plays an important role in people's lives. The significance of ethnicities and religious differences must be emphasized in the textbooks rather than describing it in simplistic way.

Another study by Dejene [10] evaluated Ethiopian Primary School Second Cycle Social Studies textbooks from multicultural perspectives. Dejene used the Bennett's model for a comprehensive multicultural curriculum as a framework to analyze the said textbooks. The findings revealed that the textbooks reflect multiculturalism. However, females were found underrepresented in the textbooks on some gender related characteristics.

Related studies cited above all deal with multicultural elements representation in social Sciences textbooks, and were all done in other countries. Findings revealed that multicultural elements were reflected in Social Science textbooks but the degree of infusion varies in each textbook. Furthermore, the researchers observed limited available empirical studies on textbook analysis using multicultural element representation as a framework especially on Science textbooks. Thus, the researchers wanted to explore other subject field such as Science to assess or evaluate its multicultural contents. The present study aims to analyze the Science Learner's Manual for Grade 10 in order to determine 
answers to the following questions:

1. What are the frequencies of four core values of comprehensive multicultural curriculum in the textbook?

2. Which among the four core values of comprehensive multicultural curriculum is prevalent?

3. Is there is a significant difference in the distribution of elements based on Bennett's four core values?

4. What are the frequencies of male and female figures occurrences?

5. Is there a significant difference in the occurrences of male and female figures in the textbook?

\section{Method}

In the Philippine K-12 basic education curriculum, it is stated that Science education aims to develop scientific literacy among learners that will prepare them to be informed and participative citizens who are able to make judgments and decisions regarding applications of scientific knowledge that may have social, health, or environmental impacts. The Science curriculum recognizes the place of Science and technology in everyday human affairs. It integrates Science and technology in the social, economic, personal and ethical aspects of life. The Science curriculum promotes a strong link between Science and technology, including indigenous technology, thus preserving our country's cultural heritage.

According to Khine [19], in analyzing Science textbooks, researchers should look into the balance between theoretical and practical knowledge, portrayal of minorities, women and gender fairness, treatment of socio-scientific and controversial issues, and depiction of graphical information, vocabulary load, comprehensibility, and readability at intended level, accuracy, and coherence, representation of indigenous knowledge, the role of textbook questions, dealing with misconceptions, and cultural and religious sensibility. With these concepts in mind, the researchers aim to evaluate the Science Learner's Material for Grade 10 for its multicultural element representations and gender fairness.

The textbook that was analyzed was entitled Science Learners' Manual for Grade 10. It is a textbook published by the Department of Education and printed in the Philippines by REX Book Store, Inc. It is currently being used by $10^{\text {th }}$ graders junior high school in all the public schools nationwide. This book was collaboratively developed and reviewed by educators [1] from public and private schools, colleges, and/or universities. The researchers chose this textbook because she used it in teaching Science for Grade 10 .

Thus, this study wants to explore how Science Learner's Material for Grade 10 represent multicultural elements - the Bennett's four core values of comprehensive multicultural curriculum in particular. Science textbooks are presumed to be indigenized, culturally sensitive, integrated with personal and ethical aspect of life and socially and environmentally in favor as insinuated in the k-12 basic education curriculum.

The study adopted the conceptual model of comprehensive multicultural curriculum suggested by
Bennett. This model was used by Dejene [10] in his evaluation of Ethiopian Primary School Second Cycle Social Studies textbooks from multicultural perspectives and Clark [7] in his study entitled Productive Dissonance: A Musical-Analytic Exploration of Teacher Educator Perceptions in a Multicultural Education Program.

As cited by Dejene [10], Bennett [5] suggested four core values of multicultural education that should be addressed in comprehensive multicultural curriculum, these are: respect for human rights and human dignity, acceptance and appreciation and diversity, responsibility to the world community, and respect to the earth. She further identified objectives of a multicultural curriculum and six major goals of comprehensive multicultural curriculum: (a) valuing multiple historical perspectives; (b) possessing cultural consciousness (understanding of one's own culture); (c) strengthening intercultural competence; (d) acquiring intercultural competence; (e) increasing awareness of the state of the planet and the global dynamics; and (f) developing social action skills.

In order to easily extract those data that reflect multiculturalism in the form of words, phrases, pictures, paragraphs, headings and task, the researchers find a set of words that describe or give a comprehensive meaning to the four core values of Bennett's [5] comprehensive multiculturalism curriculum. These are as follows:

a) Human dignity and human rights and issues, all human beings are born free and equal in dignity and rights. Human dignity is the state of being worthy of honor or respect (Oxford English Dictionary).

b). Appreciation and acceptance of diversity, the ability to understand and accept the worth, quality of diversity in race, culture, beliefs, religion, socio-economic status, linguistic and other characteristics that make an individual different from others.

c) Responsibility to the world community, it is the responsibility of the individual to watch over a community to make sure that standards are objective and beneficial to human life.

d) Respect to the state of the earth, this is the ability to appreciate the importance of environment and the earth as a whole and be able to act as a stewards in protecting and preserving the Mother Nature.

Another concept addressed in multicultural education is gender equality. Some studies contend that multicultural curriculum must promote gender equal representation in the textbooks. The fact that the textbooks provide the orthodox gender image of the world that inevitably inspires students (boys and girls) to adopt or assume, textbook developers must take extra care in constructing gender images because whatever it depicted in the textbooks will be followed or idolized by the students.

Content analysis was employed in this study. In content analysis, both "manifest content" i.e. the visible, surface content and "latent content" or the underlying meaning of manifest content was examined. The researchers read and analyzed the content of the textbook based on the definition 
or set of words given above, and latent content analysis then transcribed it on the checklist (Table 1) that was developed based on Bennett Conceptual model of comprehensive multiculturalism. After analyzing the data, the distribution and frequency of the core values were tallied, and calculated for its percentage and chi square test.

Table 1. Multicultural variables.

\begin{tabular}{|c|c|c|c|c|c|c|c|}
\hline Variables & Words & Phrases & images & Paragraphs & heading & Tasks & total \\
\hline $\begin{array}{l}\text { A. Human dignity and human rights issues } \\
\text { B. Appreciation and acceptance of diversity } \\
\text { C. responsibility to the world community } \\
\text { D. respect to the state of the earth }\end{array}$ & & & & & & & \\
\hline
\end{tabular}

Furthermore, although gender representation in the textbooks could have been treated under Bennett's second core value i.e. appreciation and acceptance of diversity, the researchers examined it separately. Accordingly, the textbook analysis was done by referring the representations of male and female characters in texts as noun (names), pronoun (she, he, her, hiss etc...), and common noun (boy, girls, men, women etc...) and their visual representations.

Table 2. Gender Representation in Science Learner's Material for Grade 10.

\begin{tabular}{lll}
\hline Gender & Represented in words & Represented in images \\
\hline Female & & Total \\
Male & \\
\hline
\end{tabular}

\section{Results and Discussion}

The study examined the content of the Science Learner's Material for Grade 10 from multicultural components and elements. The textbook was evaluated from Bennett's comprehensive multicultural curriculum core values i.e. respect to human rights and dignity, acceptance and appreciation of diversity, responsibility to the world community and respect to the earth. For this purpose, a content analysis research method was employed and the data collected was analyzed and interpreted using percentages and chi square. This section presented and interpreted the data results. The first question of this study on what are the frequencies of four core values of comprehensive multicultural curriculum in the textbook was answered by the data presented in the following table.

Table 3. Multicultural variables representation in Science Learner's Material 10.

\begin{tabular}{llllll}
\hline Variables & Unit 1 & Unit 2 & Unit 3 & Unit 4 & N \\
\hline Human dignity and Human rights and Issues & 0 & 4 & 6 & 0 & 10 \\
Appreciation and acceptance of diversity & 40 & 6 & 10 & 10 & 6.98 \\
Responsibility to the world community & 6 & 1 & 4 & 3 & 14 \\
Respect to the state of the earth & 6 & 0 & 16 & 0 & 12.92 \\
Total multicultural variables & 52 & 11 & 36 & 13 & 112 \\
\hline
\end{tabular}

Table 3 shows the frequency numbers that each core values reflected in the textbook and their distribution from unit one to four as well as the percentage. As can be seen, Science Learner's Material for Grade 10 reflected multicultural issues such as human dignity; appreciation and acceptance of diversity; responsibility to the world community; and respect to the state of the earth. However, the degrees of representation differ in each unit.

In unit 1 , the core value appreciation and acceptance of diversity was reflected more with high frequency level of fourthly (40), then the core values responsibility to the world community and respect to the state of the earth got tie scores of six (6), while human dignity and human rights and issues got zero appearance. The title of unit one is "Earth and Space" with two modules that focuses on plate tectonics, plate boundaries and other frameworks that are related to several geologic changes of the earth. The modules recognized different places in the world such as the Philippine islands, Hawaiian Islands, America, Antarctica and other places that are involves $n$ the plate boundaries. That is the reason why the core value appreciation and acceptance of diversity appeared more in this unit. However, the core value human dignity and human rights got zero appearance in this unit simply because unit one focuses on geological features of earth such as the relationship among volcanoes, earthquake epicenters, mountain ranges, interior structure of the earth, lithospheric plate movements and other earthly related issues where incorporation or infusion of the core value human dignity and human rights issues are not that fit or appropriate.

In unit two (2), the first three variables were visualized except the fourth one which is respect to the state of the earth. The core value human dignity and human rights recognized in this unit four (4) times, appreciation and acceptance of diversity appeared six (6) times, and responsibility to the world community recognized only once in this unit, while respect to the state of earth got zero appearance. The title of this chapter is "Force, Motion, and Energy". This unit focuses on electricity and magnetism, electromagnetic spectrum, and light: mirrors and lenses-incorporating ecological conservation is not apposite or suitable. Furthermore, this scientific knowledge presented in 
the textbook in a series of inquiry-based activities and or structured experimentations.

The unit three (3) undeniably elaborate the four core values, with a unit title of "Living Things and Their Environment", human dignity and human rights depicted six (6) times, appreciation and acceptance to diversity appeared ten (10) times, responsibilities to the world community depicted four (4) times, and respect to the state of the earth got the highest representation of sixteen (16).

Lastly, the unit four (4) which represented only the core values appreciation and acceptance to diversity with a frequency of ten (10), and responsibility to the world community that appeared three (3) times. While human dignity and human rights as well as respect to the state of the earth got zero appearance in this unit. Unit four is about Matter and its Interactions, employment of human dignity and human rights issues as well as respect to the state of the earth seem like inappropriate.

In the field of Science where all the topics are believed to be static, absolute, scientific and theoretical knowledge, the opportunities to infuse multicultural elements is not easy or well-matched. So, a simple appreciation or recognition of diverse characteristics of an individual in the textbook can be considered as reflection or depiction of multiculturalism. Moreover, teachers play a significant part in infusing a wide repertoire of multicultural contents in the Science topics that promote understanding among students from diverse backgrounds, interests, and abilities. Furthermore, to be effective, educators must possess the multicultural knowledge, attitudes, and behaviors that appropriately respond to issues of student diversity and cross-cultural acceptance and validation [6 \& 21 as cited by 23].

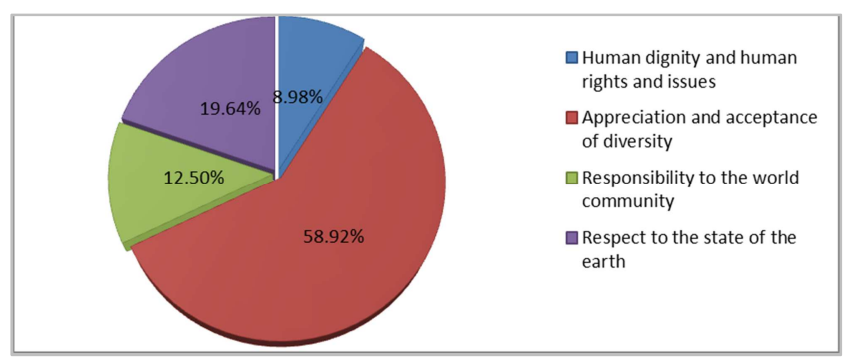

Figure 1. Percentage distribution of the Four Core Values in the textbook.

Figure 1 portrays the percentage variation of multicultural variables representation in the textbook. As shown, the core value appreciation and acceptance of diversity ranked as number one with a high percentage of 58.92, this figure answered the second question on this study on which of the four core values are more common or is prevalent in the textbook. Respect to the state of the earth with $19.64 \%$ ranked as second. Followed by the variable responsibility to the world community and have a percentage of $12.50 \%$, and lastly the human dignity and human rights and issues with a percentage of $8.98 \%$.

The distribution of elements based on Bennett's four core values was also evaluated if there is a significant difference. The result is presented in the following table.
Table 4. The distribution of the four core values in the textbook.

\begin{tabular}{llllll}
\hline Core values & O & E & df & $\mathbf{X}^{\mathbf{2}}$ & P-Value \\
\hline Respect for human right & 10 & 28 & 3 & $1,965.25$ & 7.815 \\
Diversity & 66 & 28 & & & \\
Responsibility & 14 & 28 & & & \\
Respect to Earth & 22 & 28 & & & \\
\hline
\end{tabular}

Table 4 data revealed that there is a significant difference in the representation of the four core values in the Science Textbook. Based on the chi square test result, it shows that there is significant difference in representation among the four values of comprehensive multicultural curriculum in the related textbook $\left(\mathrm{X}^{2}=1,965.25 \mathrm{df}=3, \mathrm{p}>0.05\right)$. This implies that there is an extensive variation of presenting multicultural core values in each unit of the Science textbook. This data was supported by the frequency distribution of the four core values shown in table three (3) where some variables got zero appearance or frequency level in unit one, two and four.

This study examined the frequencies of male and female figure occurrences and if there is a significant difference in the occurrences of male and female figures in the textbook. For this purpose, gender representation was analyzed in terms of nouns, pronouns, common nouns and pictures/images. Results are presented below in Tables 5 and 6 .

Table 5. Gender representation in terms of words (noun, pronoun, common nouns etc).

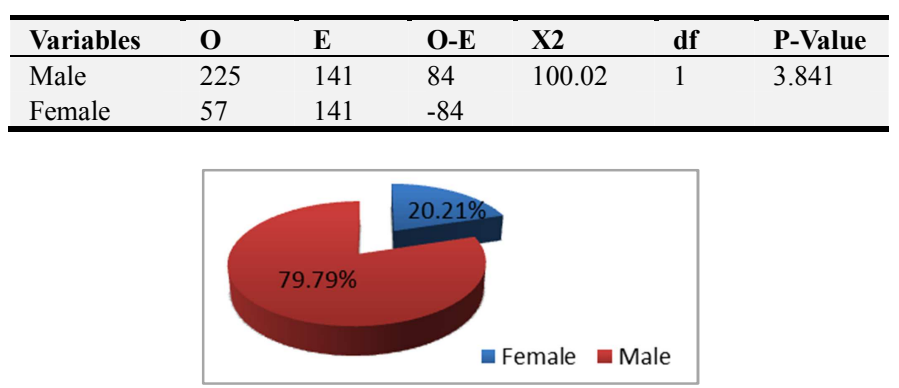

Figure 2. Percentage of Gender representation in terms of words.

The data shows that there is a significant difference of gender representation in the textbook. The chi square test result was statistically significant at $X^{2}=100.02, \mathrm{df}=1$, $\mathrm{p}<0.05$. It suggested that males are frequently represented than females in terms of words; nouns, common nouns, and pronouns, with a frequency level of 225 or $79.79 \%$, while females appeared 57 only or $20.21 \%$.

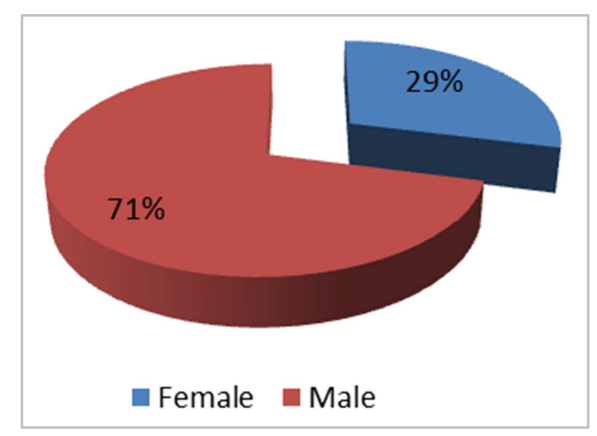

Figure 3. Percentages Gender representation in Images. 
Table 6. Gender representation in image/ pictures.

\begin{tabular}{lllllll}
\hline Variables & O & E & O-E & X2 & df & p-value \\
\hline Male in picture & 27 & 19 & 8 & 6.73 & 1 & 3.841 \\
Female in picture & 11 & 19 & -8 & & & \\
\hline
\end{tabular}

As indicated in Table 6, the result of the chi square test shows that there is a significant difference among the frequency of pictorial representation of males and females. The chi square test is found to be significant at $X^{2}=6.73, \mathrm{df}=1$, $\mathrm{p}<0.05$. Again, males appeared more than female figures, with a percentage of $71 \%$ while females got only $29 \%$ appearance in the textbook.

Findings reveal that gender inequalities also exist in the textbook. Females found underrepresented in the textbook. Males mostly appeared in the textbook either in words or pictures. Males are depicted in the textbook as theorists, activists, sporty and the like while females are depicted as beautiful, loves to eat and with motherly figure. The statement that gender equality in the society is just a slogan made sense in this study. Additionally, gender disparities in textbooks, which was highlighted in the study of Dejene [10] are likewise affirmed in this study.

\section{Conclusion and Recommendations}

In conclusion, the Science Learner's Material for Grade elusively reflected multiculturalism. It needs further elaboration from the teacher, so the students can appreciate the presence of that certain core values in the textbook. As stated in the book of Hernandez [15], an individual teacher can and do make a difference in student learning and to a great extent, determines the degree to which education is truly multicultural [11].

As to gender representation, and despite efforts done by the Department of Education thru Republic Act 10533 on gender and culture sensitivity of basic education curriculum, females are still underrepresented and gender inequality exists in Philippine basic education textbooks.

Based on the findings of the study, the researchers suggested the following:

1. For the next revision of the textbook, it is very crucial that the authors pay more attention in incorporating and elaborating multicultural elements in the subject matters of Science.

2. Science Teachers must be well equipped with knowledge of comprehensive multicultural elements so they can infuse it easily in the lesson proper.

3. The textbook authors should observe equal gender representation in the next revision of the related textbook.

4. Using other multicultural frameworks in assessing Science textbook is recommended in the future study.

\section{References}

[1] Acosta, H. D., Alvarez, L. A., Angeles, D. G., Arre, R. D., Carmona, P. P., Garcia, A. S., et al. (2015). Science Learner's Manual for Grade 10, $1^{\text {st }}$ edn. Pasig City: Rex Publishing House.
[2] Banks, J. A., \& Banks, M. B. (2001). Multicultural Education 4th Edition. USA: John Wiley \& Sons, Inc.

[3] Banks, J. A., \& Banks, C. A. M. (Eds.). (2002). Handbook of research on multicultural education (2nd ed.). San Francisco: Jossey-Bass.

[4] Banks, J. \& C. McGee Banks [eds]. (2010). Multicultural Education: Issues and Perspectives. USA United States.

[5] Bennett, C. I. (2003). Comprehensive multicultural education: Theory and practice. Boston: Allyn and Bacon.

[6] Brown, E. (2004). What precipitates change in cultural diversity awareness during a multicultural course: The message or the method? Journal of Teacher Education 55, 325-340.

[7] Clark, L. V. (2010). Productive Dissonance: A MusicalAnalytic Exploration of Teacher Educator Perceptions in a Multicultural Education Program. International journal of multicultural education, 1-15.

[8] Cobern, W. W., \& Loving, C. C. (2018). Defining "Science" in a Multicultural World: Implications for Science Education. John Wiley \& Sons, Inc., 1-16.

[9] Deauna, M. C. (1996). Elementary Statistics for Basic Education. Quezon City: Phoenix Publishing House, Inc.

[10] Dejene, W. (2017). Assessing Ethiopia Primary SchoolSecond Cycle Social Studies Textbooks for Adequate Reflections of Multiculturalism. Journal of Education and Practice, 1-10.

[11] Frazier, L. (1977). The multicultural facet of education. Journal of Research and Development in Education, 11 (1), 10-16.

[12] Gaul, A. (2014). Where are the Minority? The elusiveness of Multiculturalism and Positive Recognition in /sri Lankan History Textbooks. Journal of Education Media, Memory, and Society, 1-20.

[13] Gay, G. (2004). The Importance of Multicultural Education II. Educational Leadership, 1-8.

[14] Gonzales, E. T. (2005). Managing Diversity in the Philippines: Is Government working hard to provide services in equal ways? Retrieved October 16, 2018, from www.napsipag.org $>$ pdf $>$ gonzaleze.

[15] Hernandez, H. (2001). Multicultural Education: A Teacher's Guide to Linking Context, Process, and Content, 2nd Edition. New Jersey: Prentice-Hall, Inc.

[16] Implementing Rules and Regulations of the enhanced Basic Education Act of 2013. (n.d.). Retrieved October 16, 2018, from Official Gazette: http://www.officialgazette.gov.ph

[17] Jackson, L. (2016). Learning about diversity in Hong Kong; Multiculturalism in Liberal Studies Textbooks. The AsiaPacific Educational Researcher, 1-26.

[18] K-12 Science Curriculum Guide. (2013). Retrieved October 15, 2018, from DepEd Tambayan: http://depedtambayan.ph.blogspot.com.

[19] Khine, M. S. (2013). The analysis of Science Textbooks for Instructional Effectiveness. Research Gate, 1-8.

[20] Palces, K. M., Abulencia, A. S., \& Reyes, W. M. (2015). Predicting the Priorities of Multicultural Education in a Philippines Teacher Education Institution: An exploratory study. EDUCARE: International Journal for Educational Studies, 1-10. 
[21] Pang, V. O. (2001). Multicultural education: A caringcentered, reflective approach. New York: McGraw-Hill

[22] Stoilescu, D. (2014). A Critical Multicultural Analysis of a Romanian Textbook Taught in Elementary International Language Programs. Acta Didactica Napocensia, 1-16.

[23] Sy-Luna, G. (2015). Multicultural education Program in Far Eastern University: A Basis for Enhancement. Retrieved october 17, 2018, from http://icsa.org.procarch.

[24] Tarrayo, V. N. (2014). Gender Word (or World): Sexism in
Philippines Preschool English Language Textbook. iManager's Journal on English Language Teaching, 1-8.

[25] Terra, L., \& Bromley, P. (2012). The Globalization of Multicultural Education in social Science Textbook: Crossnational analyses, 1950-2010. Research Gate, 1-9.

[26] Zuñiga VI, R. C. (2010). "Multicultural Education: Introduction". Available online also at: http://chamzun.blogspot.com/2010/09/multiculturaleducation-introduction.html. 